\title{
Survey on the microbiological quality of Chinese food preparations
}

\author{
P. Catellani $\cdot$ L. Alberghini $\cdot$ S. Feletti $・$ V. Boldrin
}

Published online: 21 May 2010

(C) Springer Science+Business Media B.V. 2010

\begin{abstract}
The microbiological quality of 118 samples of traditional Chinese food from restaurants and take-away establishments in the provinces of Padua, Treviso, and Venice was examined (April-July, 2008). These food items included various ready-to-eat products. The microbiological quality of the majority of these food items was acceptable; only $12 \%$ of samples had values greater than or equal to $6 \log \mathrm{CFU} / \mathrm{g}$ (eight items were salads) and $19 \%$ of samples had values greater than $500 \mathrm{CFU}$ fecal coliforms $/ \mathrm{g}(p<0.01$ to 0.001$)$. The Aw lower values were in sauces (0.839), but were greater than 0.95 in other food sources. No pathogens, such as Salmonella spp. or Listeria monocytogenes, were detected, but Bacillus cereus and coagulase-positive Staphylococcus were both identified. Thus, although final heating reduces the levels of microorganisms present in foods, it does not inactivate any toxins produced by such organisms.
\end{abstract}

Keywords Food microbiology $\cdot$ Chinese restaurants · Take-away Ready-to-eat foods

\author{
Abbreviations \\ ISO International Organization for Standardization \\ CMT Total aerobic microbial count \\ $\mathrm{A}_{\mathrm{w}} \quad$ Activity water \\ GMP Good manufacturing practice
}

P. Catellani $(\bowtie) \cdot$ L. Alberghini

Department of Public Health, Comparative Pathology and Veterinary Hygiene, Faculty of Veterinary Medicine, University of Padua,

Viale dell'Università, 16, Agripolis, 35020 Legnaro, PD, Italy

e-mail: paolo.catellani@unipd.it

S. Feletti

Via Indipendenza 129, 31030 Arcade, TV, Italy

V. Boldrin

Via Gramsci 29, 30010 Campagna Lupia, VE, Italy 


\section{Introduction}

Ethnic Chinese restaurants began to emerge in Western countries after the First World War due to a substantial influx of Chinese people attributed to economic hardships that persisted in the East for years. However, since the 1980s, Chinese food has become more common in Western countries in connection with general complex and changing dietary habits and the resulting phenomenon of take-away restaurants. Today, in Italy there are many typical Chinese restaurants. Being able to quantify with strict numerical terms the restaurants and caterers currently on our territory is almost impossible. Indeed, these establishments are difficult to count because of the speed with which they appear and disappear. Additionally, their registration is often on behalf of Italians who present themselves as sole proprietors. Milan and Rome remain safe cities with the largest number of local ethnic Chinese, but the spread is ubiquitous and constantly increasing. In Italy, there is also a specialist food market developing. For example, we report in Table 1 food imports from China in the province of Padua between 2000 and 2006, which shows that imported food has evolved steadily over the years and that canned foods prevail among all the products. However, foods are not the main goods imported from this country. In 2006, the value of food imports was only about $1 \%$ of total imports in the province of Padua (Source CCIAA 2007).

A considerable import market has grown in recent years, and Chinese cuisine has maintained a relatively low cost. Factors that contribute to the low price of food are that restaurant businesses often operate as part of a family, the cooking methods used are quite fast and require a minimum expenditure of fuel, and that it is basically poor cooking without wasting of ingredients. The ingredients include mostly large quantities of grains and vegetables and minimal meat and fish. The desire to maintain the customs, traditions, and modes of operation typical of oriental cultures sometimes makes it difficult to have a constructive confrontation with the institutional bodies responsible for monitoring our territory. Unfortunately, veterinary supervision often reveals infringements relating to dirt, sanitation and structural deficiencies, lack of adequate clothing for employees in the kitchens, inadequate conservation of food, presence of insects and rodents in stores and in local food, and raw materials from China that have been subjected to treatments of sophistication or adulteration. If food is prepared, stored, and administered improperly, it can endanger human health and cause disease. For example, in Chinese restaurants there have been numerous reports in recent decades attributable to $S$. aureus, $C$. perfringens, $V$. parahaemolyticus (Davis et al. 2004), B. subtilis (Shi et al. 2006), and Salmonella spp. (Padmanabhan et al. 2004). In Italy during 2003, a case of poisoning by B. cereus involved a dozen people who had eaten a dish made of shrimp and bean sprouts with steamed rice

Table 1 Distribution of food imports from China destined for the province of Padua. Absolute value in Euro. Source: CCIAA, year 2007

\begin{tabular}{llllll}
\hline Year & Meat & Fish & Canned foods & Vegetables and fruits & Beverage \\
\hline 2000 & 1.640 .460 & 36.014 & 2.641 .123 & 474.770 & - \\
2001 & 1.273 .139 & 87.610 & 3.272 .313 & 355.312 & - \\
2002 & 519.218 & - & 3.069 .086 & 650.551 & - \\
2003 & 469.253 & 208.445 & 2.541 .592 & 546.660 & - \\
2004 & 149.619 & 19.893 & 3.622 .302 & 571.048 & - \\
2005 & 823.244 & - & 5.274 .736 & 1.051 .164 & - \\
2006 & 1.161 .456 & 29.501 & 3.796 .797 & 1.369 .059 & 4.328 \\
\hline
\end{tabular}


that was left at room temperature overnight and fried when needed. The purpose of this study was to evaluate the microbiological quality of prepared Chinese dishes from restaurants, bars, caterers, and local authorities on the Venetian territory in the provinces of Padua, Treviso, and Venice.

\section{Materials and methods}

The microbiological quality of 118 samples of traditional Chinese preparations from restaurants and take-away premises in the provinces of Padua, Treviso, and Venice were examined between April and July 2008. These samples included various types of ready-toeat products that were stored precooked for reheating on demand. Samples were collected based on an Italian division of the meal, including appetizers, first and second courses, vegetables, sauces, and cakes (Table 2). These divisions were the same at Chinese catering operations in our country although Asian cuisine includes dishes of various kinds that are served simultaneously, with no real hierarchy.

The various dishes are prepared well in advance, to allow them to be ready when requested by the customer. It was considered advisable to purchase in the few hours prior to closing. The various courses were, therefore, cooked or heated at the time of purchase and placed in aluminium containers with covers. To avoid sudden temperature changes, samples were placed in isothermal bags several minutes after cooling at room temperature and taken to the laboratory quickly where they were analyzed the next day. The analytical work focused on the search for microorganism indices of food safety and hygiene processes using the methods prescribed by the relevant International Organization for Standardization (ISO) standards. In particular, the total aerobic microbial count (CMT), total and fecal coliforms, Pseudomonas spp., coagulase-positive staphylococci, spore-forming bacteria, enterococci, moulds, and yeasts were investigated. Salmonella spp. and L. monocytogenes were investigated with qualitative analyses. Finally, the $\mathrm{pH}$ and activity water $\left(\mathrm{A}_{\mathrm{w}}\right)$ were measured for each sample. After logarithmic transformation, the microbiological data, and the physical and chemical properties were developed by univariate analysis of variance (Proc GLM, package SPSS, 2005). Tukey's HSD post hoc tests were performed wherever possible. The degree of correlation between various parameters was assessed using the method of linear regression. The experimental factors considered were ports, hot or cold, and date of withdrawal.

\section{Results}

It is noted that the CMT in the various products tested was not particularly high. The highest average values were found for the courses, dressings $\left(4.0 \log \mathrm{CFU} \mathrm{g} \mathrm{g}^{-1}\right)$, and starters (3.9 $\log )$, for the line $(\mathrm{p}<0.001)$ hot $(2.9 \log )$ and cold $(4.2 \log )$, while the date of the levy

Table 2 Number of samples collected and subjected to microbiological analysis

\begin{tabular}{llll}
\hline COURSE & N. of samples collected & COURSE & N. of samples collected \\
\hline Appetizer & 32 & Vegetables & 16 \\
First course & 14 & Sauces & 5 \\
Second course & 48 & Cakes & 3 \\
\hline
\end{tabular}


are equal (between 3.3 and $3.9 \log \mathrm{CFU} \mathrm{g} \mathrm{g}^{-1}$ ). These charges are mostly represented by Gram-negative bacteria with special reference to fecal coliforms in which the line cool $(\mathrm{p}<0.001)$ reached an average of $2.4 \log \mathrm{CFU} \mathrm{g}^{-1}$ between the flows $(\mathrm{p}<0.01)$ and prevailed in appetizers $\left(2.6 \log \mathrm{CFU} \mathrm{g}^{-1}\right)$. Pseudomonas spp. was present with a maximum load of $2.9 \log \mathrm{CFU} \mathrm{g}{ }^{-1}$ in appetizers. The Gram positive lactobacilli that prevailed and the line micrococcacee cold $(\mathrm{p}<0.001)$ had values of 5.2 and $3.0 \log \mathrm{CFU} \mathrm{g}{ }^{-1}$, respectively. Coagulase-positive staphylococci were present at maximum loads of 2.3 $\log \mathrm{CFU} \mathrm{g} \mathrm{g}^{-1}$ in outline and in the period March/April. In particular, in a sample of "bamboo with Chinese mushrooms" taken at a restaurant, the charge was $5.5 \log$ CFU g ${ }^{-1}$. Other samples taken the same day from the same location showed similar values (4.0 log CFU $\left.\mathrm{g}^{-1}\right)$. The $\mathrm{pH}(\mathrm{p}<0.001)$ is acid dressings (4.58) and moderately acids were the vegetables (5.89) and appetizers (5.92), even in the cold line was 5.80 as compared to the warm line $(6.51)$. The $A_{w}(p<0.001)$ was lower in cakes $(0.625)$, mainly consisting of biscuits, and sauces $(0.839)$, than in other courses that were greater than 0.95 . The effects of interaction and their significance in line to reach and microbial and chemical-physical parameters are presented in Table 3.

Salmonella spp. and L. monocytogenes were never found. Through biochemical identification, three strains of B. cereus (shrimp toast, mayonnaise, shrimp dumplings and meat), two strains of non-enterotoxic $S$. aureus (crab with bean sprouts, spicy vegetables and shrimp), one strain of $A$. hydrophila/caviae (crab and bean sprouts), and one strain of $P$. aeruginosa (fried algae) were identified.

\section{Discussion}

Therefore, the ethnic Chinese restaurants on the island Venetian were not particularly critical in terms of sanitation. In $12 \%$ of the samples analyzed, eight salads had CMT values of $\geq 10^{6} \mathrm{CFU} \mathrm{g}^{-1}$. Dishes that showed a strong and fast heat treatment before being served $(60 \%)$ had CMT values $\leq 10^{3} \mathrm{CFU} \mathrm{g}^{-1}$. Nineteen percent of the samples, including three salads, made full fecal coliforms $\geq 500 \mathrm{CFU} \mathrm{g}^{-1}$. However, it is important during a standby to never lower our guard, because the personnel working in these places do not always consider the good manufacturing practice (GMP) with due importance involving food

Table 3 Interactions of scope and type of line (hot or cold). Mean values of microbial loads ( $\log C F U \mathrm{~g}^{-1}$ ) and physical-chemical parameters

\begin{tabular}{|c|c|c|c|c|c|c|c|c|c|c|}
\hline \multirow[t]{2}{*}{ Line } & \multicolumn{2}{|c|}{ Appetizer } & \multicolumn{2}{|c|}{ First course } & \multicolumn{2}{|c|}{ Second course } & \multicolumn{2}{|c|}{ Vegetables } & \multirow[t]{2}{*}{ ES } & \multirow[t]{2}{*}{ SIGN } \\
\hline & Hot & cold & Hot & cold & Hot & cold & Hot & cold & & \\
\hline CMT & 2.6 & 5.0 & 3.3 & 4.9 & 3.0 & 3.9 & 2.0 & 3.8 & 0.63 & NS \\
\hline Total coliforms & 1.9 & 4.4 & 1.7 & 4.5 & 2.1 & 2.6 & 1.7 & 2.1 & 0.38 & $* * *$ \\
\hline Fecal coliforms & 1.9 & 4.4 & 1.7 & 3.0 & 2.0 & 2.0 & 1.7 & 1.9 & 0.23 & $* * *$ \\
\hline Micrococcaceae & 1.7 & 4.1 & 1.7 & 2.3 & 2.0 & 2.7 & 2.1 & 2.5 & 0.35 & $* *$ \\
\hline Coagulase-positive staphylococci & 1.7 & 2.5 & 1.9 & 1.9 & 2.0 & 2.0 & 2.9 & 2.1 & 0.27 & $*$ \\
\hline Pseudomonas spp & 2.0 & 3.6 & 1,9 & - & 2.6 & 2.3 & 2.1 & 2.8 & 0.64 & NS \\
\hline $\mathrm{pH}$ & 6.33 & 5.56 & 6.91 & 6.92 & 6.49 & $6 ., 21$ & 6.15 & 5.81 & 0.29 & NS \\
\hline$A_{w}$ & 0.941 & 0.971 & 0.970 & 0.960 & 0.982 & 0.945 & 0.982 & 0.945 & 0.02 & NS \\
\hline
\end{tabular}

The significance $(\alpha=0.05)$ and NS: not significant $*: \mathrm{p}<0.05, * *: \mathrm{p}<0.01, * * *: \mathrm{p}<0.001$ 
handlers, cross-contamination, and poorly keeping food. Additionally, there is a large cultural gap between the different concepts of health standards of the home country and Western countries. No pathogens such as Salmonella spp. and L. monocytogenes were isolated, but $B$. cereus and coagulase-positive staphylococci were identified. Hence, although final heating reduces the levels of microorganisms present in foods, it could not inactivate any toxins if present.

\section{References}

Davis CR, Heller LC, Peak KK, Wingfield DL, Goldstein-Hart CL, Bodager DW, Cannons AC, Amuso PT, Cattani J (2004) Real-time PCR detection of the thermostable direct hemolysin and thermolabile hemolysin genes in a Vibrio parahaemolyticus cultured from mussels and mussel homogenate associated with a foodborne outbreak. J Food Prot 67(5):1005-1008

Padmanabhan B, Torbjorn S, Hamid M, Richard K (2004) An outbreak of Salmonella Enteritidis phage type 34a infection associated with a Chinese restaurant in Suffolk, United Kingdom. BMC Public Health 4:40

Shi F, Xu Z, Cen P (2006) Efficient production of poly-gamma-glutamic acid by Bacillus subtilis ZJU-7. Appl Biochem Biotechnol 133(3):271-282

Source CCIAA (2007)- The Italian Chamber of Commerce (Padua). 